\title{
Research Article Optical Clearing of Cranial Bone
}

\author{
Elina A. Genina, ${ }^{1}$ Alexey N. Bashkatov, ${ }^{1}$ and Valery V. Tuchin ${ }^{1,2}$ \\ ${ }^{1}$ Research-Educational Institute of Optics and Biophotonics, Saratov State University, Astrakhanskaya Street, \\ 83, Saratov 410012, Russia \\ ${ }^{2}$ Laser Diagnostics of Technical and Living Systems Lab, Institute of Precise Mechanics and Control of RAS, \\ 24 Rabochaya Street, Saratov 410028, Russia
}

Correspondence should be addressed to Elina A. Genina, eagenina@yandex.ru

Received 20 February 2008; Accepted 2 April 2008

Recommended by Stoyan Tanev

\begin{abstract}
We present experimental results on optical properties of cranial bone controlled by administration of propylene glycol and glycerol. Both transmittance and reflectance spectra of human and porcine cranial bone in vitro were measured. For estimation of absorption and reduced scattering coefficients of the bone, the inverse adding-doubling method was used. The decrease of reflectance of the samples under action of the immersion agents was demonstrated. The experiments have shown that administration of the immersion liquids allows for effective controlling of tissue optical characteristics that makes bone more transparent, thereby increasing the ability of light penetration through the tissue. The presented results can be used in developing of functional imaging techniques, including OCT.
\end{abstract}

Copyright (C) 2008 Elina A. Genina et al. This is an open access article distributed under the Creative Commons Attribution License, which permits unrestricted use, distribution, and reproduction in any medium, provided the original work is properly cited.

\section{INTRODUCTION}

Interest in using optical methods in the development of noninvasive clinical functional cerebral imaging systems for physiological-condition monitoring $[1,2]$, cancer diagnostics, and therapies $[3,4]$ increases due to their simplicity, safety, and low cost in contrast to conventional X-ray computed tomography, magnetic resonance imaging, and ultrasound imaging [5-8]. Spectroscopic techniques are capable of deep imaging of tissues that could provide information of blood oxygenation and tissue metabolism $[1,2,9,10]$ and detect brain malignancies $[4,11,12]$. However, the main limitations of the optical imaging techniques, including diffusion optical tomography, optical coherent tomography, and reflectance spectroscopy deal with the strong light scattering in superficial tissues, which cause decrease of spatial resolution, low contrast, and small penetration depth. One of the prospective solutions of the problem is a reduction of light scattering of the upper tissue layers that provides improvement of image quality and precision of spectroscopic information getting from tissue depth $[5,13-15]$.

It is well known that the major source of scattering in tissues and cell structures is a refractive index mismatch between cell organelles, like mitochondria and cytoplasm, extracellular media and tissue structural components such as collagen and elastin fibres [5]. The tissue scattering properties can be significantly changed due to action of immersion liquids [15-20]. Administration of the immersion liquid having a refractive index higher than that of tissue interstitial fluid and/or hyperosmotic properties induces a partial replacement of the interstitial fluid by immersion substance and hence matching of refractive indices of tissue scatterers and the modified interstitial fluid. The matching, correspondingly, causes the decrease of scattering. As immersion liquids aqueous solutions of glucose and mannitol, propylene glycol, glycerol, and other biocompatible chemicals are used [15-20].

The possibility of selective translucence of cranial bone can be very useful in developing techniques of brain functional imaging. A potential benefit of the optical clearing technique is an improvement of laser therapeutic techniques that rely on sufficient light penetration to a target embedded in tissue. Combining optical clearing with laser radiation could reduce the laser fluence required for a therapeutic effect. Another application of the optical method is a noninvasive visualization of brain blood vessels, hematomas, and small pathologic structures (including cancerous growth) 
with a high resolution. This is important for diagnosis and treatment of many diseases such as tumors of brain, vascular pathologies, and so forth. However, despite the numerous studies of optical clearing of such tissues as skin, sclera, dura mater, and so forth, the bone optical clearing is not investigated enough up to now.

In this study, we investigate optical clearing of both human and porcine cranial bone in vitro under the action of propylene glycol and glycerol.

\section{BONE STRUCTURE AND PHYSICAL PROPERTIES}

The structural components of the bones consist of an inorganic matrix (largely mineralised) and an organic matrix [21, 22]. The inorganic matrix contains calcium hydroxyapatite, which is responsible for the compressive strength of bone, and osteocalcium phosphate. The main components of the organic matrix are collagen, proteins, blood cells, and lipids [23]. The amount of bone mineral matrix is $16 \%$, the lipid content is $54 \%$, the proteins content is $16 \%$, and water contributes $16 \%$ [23]. It is the calcium and phosphorus component of the inorganic matrix that makes bone hard and rigid, and the arrangement of the collagen fibres in the organic matrix that makes it strong. Porosity of the bones is 5-10\% [23].

At microstructural length scales, cortical bone is organised into 200-300 $\mu \mathrm{m}$ diameter secondary osteons [24], which are composed of large vascular channels $(50-90 \mu \mathrm{m}$ diameter) surrounded by circumferential lamellar rings (3$7 \mu \mathrm{m}$ thick), with the so-called "cement lines" at the outer boundary [25]. At the nanostructural level, the lamellae are composed of organic type-I mineralised collagen fibres (up to $15 \mu \mathrm{m}$ in length, $50-70 \mathrm{~nm}$ in diameter, and formed by regular arrangement of subnanostructural collagen molecules) bound and impregnated with inorganic carbonated apatite nanocrystals (about $30 \mathrm{~nm}$ in length and width, 2-3 nm in thickness) $[26,27]$.

Water is of significant importance for the living bone and is one of its major components. Bone water occurs at various locations and in different binding states. Water in bone may be found associated with the mineral phase, bound to the organic phase (collagen and cement substance), or free (bulk water) $[28,29]$. The most tightly bound water is the one occupying the calcium ion coordination sites in the apatite-like crystals (about $35 \mathrm{mg}$ of water/g mineral) [30]. A significant less tightly bound fraction is water associated with collagen fibrils. In the unmineralised state as the bone matrix is laid down by obsteoblasts, the collagen fibers produced contain a large volume fraction of water (up to 60\%) [31]. During calcification, however, apatite crystals are deposited in the organic matrix, gradually displacing the osteoid water and reducing it down to a $20 \%$ volume fraction. Eventually, this fraction drops to $10 \%$ in senile bone [32]. Bulk water fills the pores of the calcified matrix, which form a network of interconnecting channels (the lacunocanalicular system), which communicate the Haversian canals (the bone vascular system) with the osteocytes, embedded in the mineralized matrix [28, 31]. This communication network serves for transport of nutrients, waste products, and signaling molecules from the vascular system to the osteocytes and vice versa. The water channels are also the transport pathways for calcium and phosphate ions flowing in and out of bone tissue, which acts as a mineral reservoir for the rest of the organism [28].

Refractive index of the whole cranial bone has been estimated by Ascenzi and Fabry [33] at various stages of mineralisation to range from 1.555 to 1.564 . Components of the tissue have the following refractive indices: apatite: $>$ 1.623 [34], hydrated collagen (type I): 1.43 [35], and lipids $\sim 1.45$ [36].

\section{MATERIALS AND METHODS}

\subsection{Materials}

For this study, five porcine and ten human cranial bone samples were used. All bone samples were cortical (or compact) bones. The samples of human cranial bone were obtained from postmortem examinations. All samples were kept in saline at temperature about $5^{\circ} \mathrm{C}$ until spectroscopic measurements. The bone samples were measured during 4-6 hours after autopsy. The area of the samples was about $25 \times$ $25 \mathrm{~mm}^{2}$. The thickness of each bone sample was measured with a micrometer in several points over the sample surface and averaged. Precision of the single measurement was $\pm 50 \mu \mathrm{m}$. Thickness of the samples varied from $1.6 \pm 0.1$ to $5.0 \pm 0.5 \mathrm{~mm}$.

In this study, the commercially available propylene glycol ("Reactive," Russia) and glycerol ("Ph. Eur.," Germany) have been used as clearing agents. The refractive index of propylene glycol and glycerol has been measured by Abbe refractometer at wavelength $589 \mathrm{~nm}$ as 1.43 and 1.47, respectively.

\subsection{Experimental setups}

The measurements of bone reflectance have been performed in the spectral range 450-1000 nm using a commercially available optical multichannel spectrometer LESA5 ("BioSpec," Moscow, Russia) with a fiber-optical probe. The scheme of the experimental setup is shown in Figure 1. The fiber optical probe consists of seven optical fibers. All fibers had $200 \mu \mathrm{m}$ core diameter and a numerical aperture of 0.22 . The central fiber delivers incident light to the tissue surface, and six fibers, placed around the central fiber, collect reflected light. Distance between the delivering and receiving fibers is $290 \mu \mathrm{m}$. As a reference, a white slab $\mathrm{BaSO}_{4}$ with a smooth surface has been used. The sample of bone was placed into cuvette with the immersion liquid. For spectrophotometric measurements, each sample was removed from the cuvette. Then the sample was again placed in the cuvette.

The total transmittance and diffuse reflectance measurements have been performed in the 800-2000 $\mathrm{nm}$ wavelength range using the commercially available spectrophotometer CARY-2415 ("Varian," Australia) with an integrating sphere (Figure 2). Inner diameter of the sphere is $100 \mathrm{~mm}$, size of the entrance port is $20 \times 20 \mathrm{~mm}$, and diameter of the exit port is 


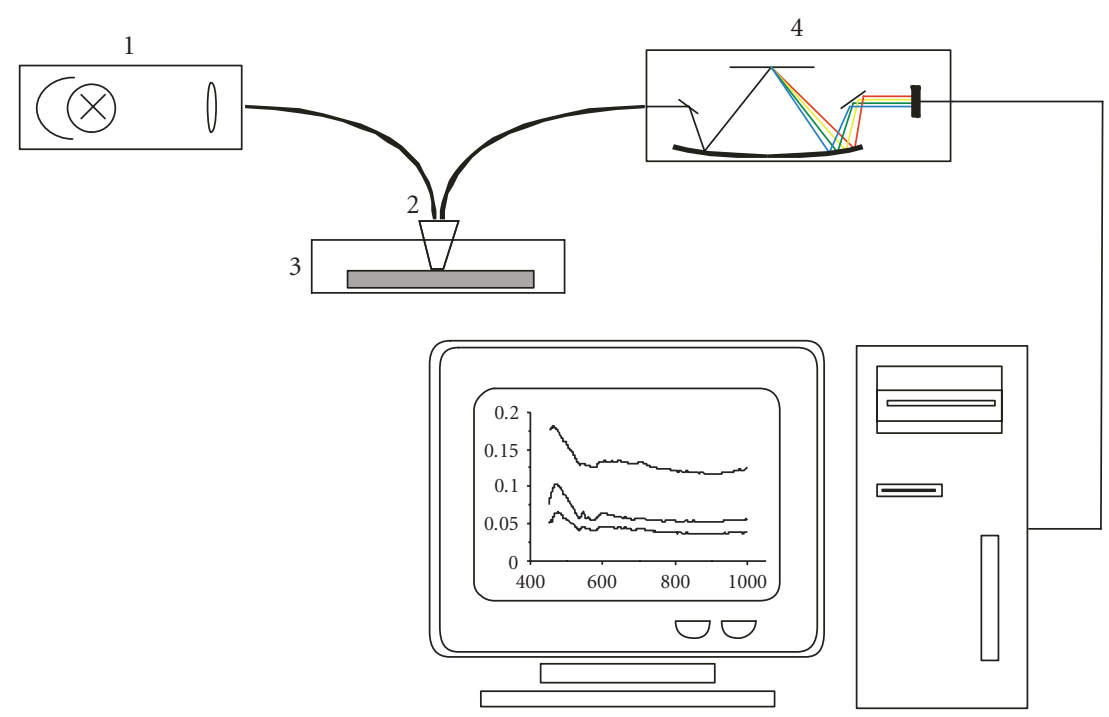

FIGURE 1: The geometry of the measurements in reflectance mode with the spectrometer LESA-5: (1) halogen lamp (2) fiber-optical probe (3) cuvette with a bone sample (4) grating and photodiode array.

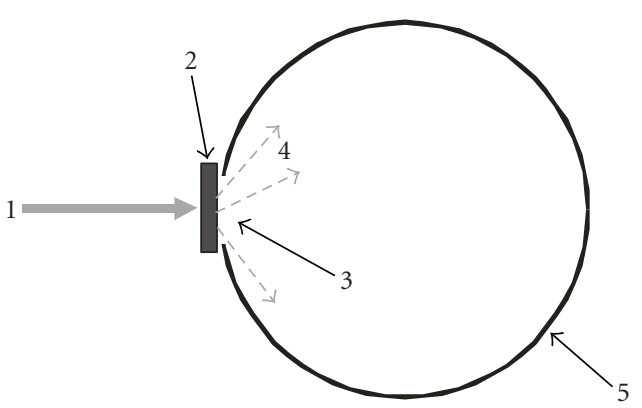

(a)

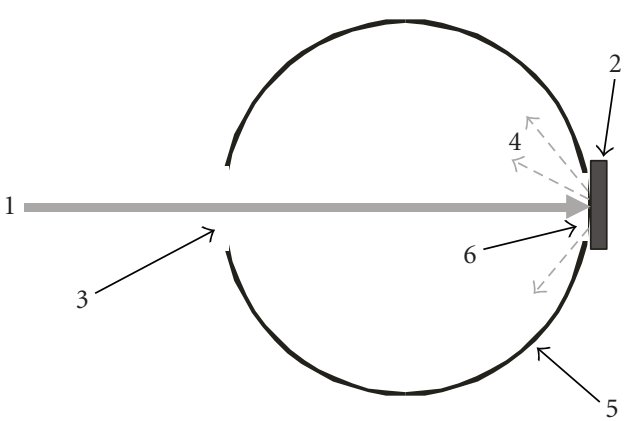

(b)

FIGURE 2: The geometry of the measurements in: (a) transmittance mode, (b) reflectance mode: (1) the incident beam (diameter 3 mm) (2) the bone sample (3) the entrance port (square $20 \times 20 \mathrm{~mm}$ ) (4) the transmitted (or diffuse reflected) radiation (5) the integrating sphere (inner diameter is $100 \mathrm{~mm}$ ) and (6) the exit port (diameter $16 \mathrm{~mm}$ ).

$16 \mathrm{~mm}$. As a light source, a halogen lamp with filtering of the radiation in the studied spectral range has been used in the measurements. The diameter of incident light beam on the tissue sample is $3 \mathrm{~mm}$. Scan rate is $2 \mathrm{~nm} / \mathrm{s}$.

The measurements were carried out at room temperature about $20^{\circ} \mathrm{C}$.

Images of cranial porcine bone during optical clearing under action of pure propylene glycol during 24 hours were obtained by a digital camera with crossed polarizers.

\subsection{Processing of experimental data}

For processing the experimental data and determination the change of the optical properties of tissue, the inverse addingdoubling (IAD) method developed by Prahl et al. [37] has been used. The method is widely used in tissue optics for processing the experimental data of spectrophotometry with integrating spheres $[38,39]$. An important advantage of the IAD method when applied to tissue optics is a possibility of rapidly obtaining iterative solutions with the aid of up-todate microcomputers [5].

This method allows one to determine the absorption $\left(\mu_{a}\right)$ and the reduced scattering coefficients $\left(\mu_{s}^{\prime}=\mu_{s}(1-\right.$ $g)$ ) of a tissue from the measured values of the total transmittance and the diffuse reflectance. Here, $\mu_{s}$ is the scattering coefficient, and $g$ is the anisotropy factor of scattering. In these calculations, the anisotropy factor has been fixed as 0.9 , since this value is typical for the tissue in the visible and NIR spectral ranges [5].

\section{RESULTS AND DISCUSSION}

Result of cranial bone clearing can be illustrated by Figure 3 . The complete clearing of the bone took place in about 24 hours. Figure 3 shows images of cranial porcine bone before (a) and after (b) optical clearing by propylene glycol during 24 hours. The cross drawn on a paper was covered by the bone to observe the increase of the sample translucence. The 


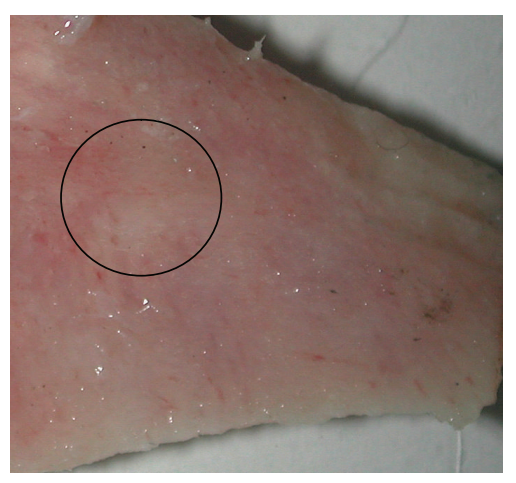

(a)

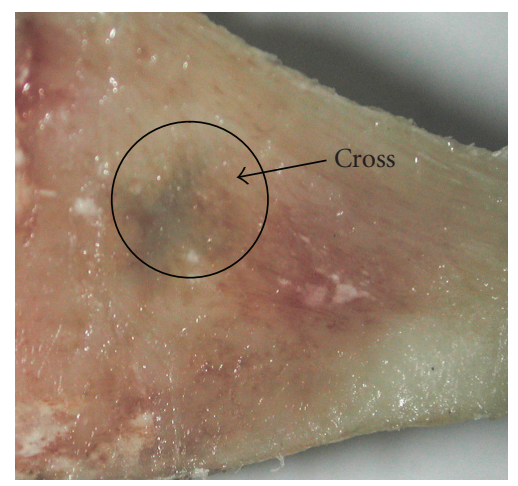

(b)

FIGURE 3: The bone sample before (a) and after (b) optical clearing by propylene glycol during 24 hours. The cross-observed through the bone is marked by an arrow.

thickness of the sample was $1.5 \pm 0.2 \mathrm{~mm}$. It is well seen that before immersion agent action the tissue was turbid, and the image of cross was not seen. After 24 hours, the bone became more transparent and the cross image was observed. Besides, blood vessels being under the bone surface were also clearly seen.

In Figure 4, spectra of reflectance of cranial porcine bone during the action of propylene glycol are presented. In the spectra, three spectral bands corresponding to blood absorption in the visible range are well seen. They are the $\alpha$-band with maximum at $537 \mathrm{~nm}$ and the $\beta$-band with maximum at $568 \mathrm{~nm}$ of oxyhemoglobin absorption [40]. Decrease of reflectance in the short-wavelength range from 450 to $470 \mathrm{~nm}$ can be connected with absorption in longwavelength wing of the Soret band of oxyhemoglobin with maximum at $415 \mathrm{~nm}$ [40]. The action of immersion agent produces the decrease of the reflectance of the bone tissue (due to decreasing light scattering in the tissue) in whole studied spectral range that indicates that bone becomes more transparent.

In the visible spectral range, significant decrease of reflectance of the sample wetted in propylene glycol in comparison with untreated sample is observed during the first few minutes. It can be explained by effective immersion of the upper layers of the sample. Further decrease of the

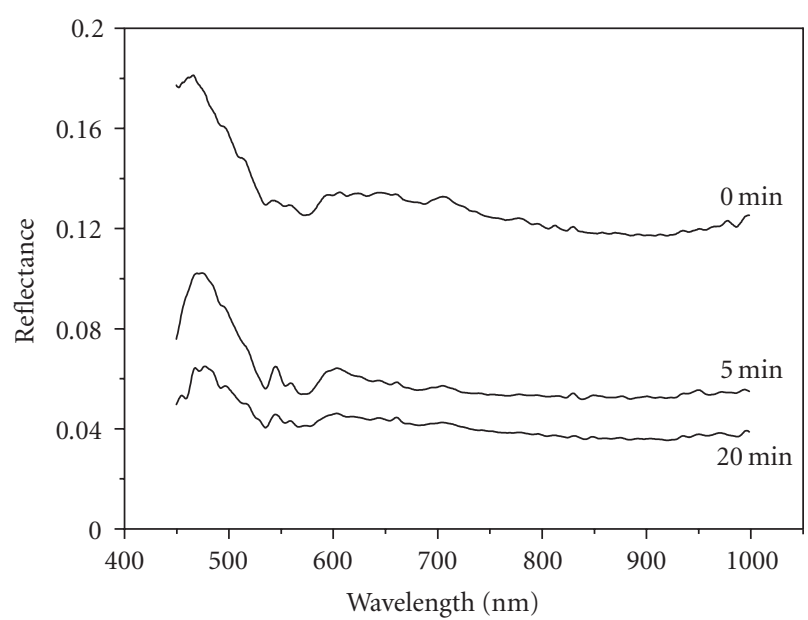

Figure 4: The reflectance spectra of the bone sample measured concurrently with administration of propylene glycol at different time intervals.

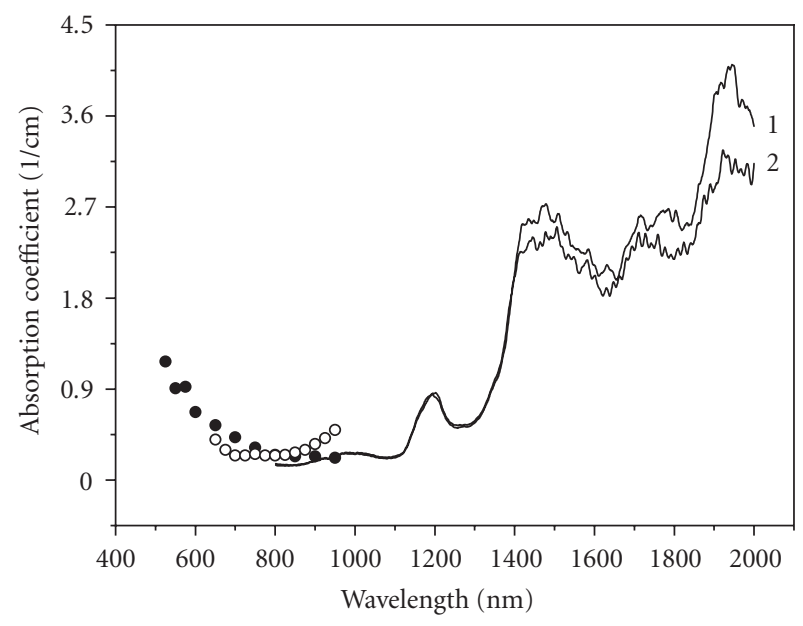

FIGURE 5: The absorption spectra of bone sample measured before (1) and after administration of glycerol (2) during an hour. Black circles correspond to data presented in [41], and open circles correspond to data presented in [42].

bone reflectance is caused by penetration of immersion agent into the sample on the depth of probing (about $100 \mu \mathrm{m}$ for the given centre-to-centre separation of the source and detector fibers) and partial matching of refractive indices of both inorganic matrix and interstitial substance.

Figures 5 and 6 demonstrate dynamics of optical properties of human cranial bone after administration of glycerol in spectral range $800-2000 \mathrm{~nm}$ calculated by IAD method on the basis of measured values of the total transmittance and the diffuse reflectance. Figure 5 presents typical wavelength dependence of the bone absorption coefficient before glycerol administration and after an hour of glycerol action. Figure 6 shows typical wavelength dependence of the reduced scattering coefficient of the bone sample before glycerol administration and after an hour of glycerol action. 


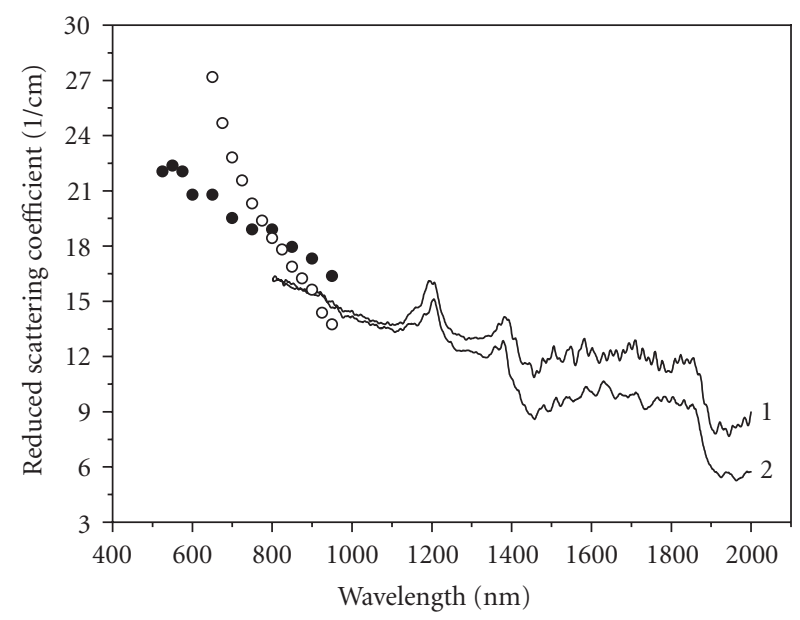

FIGURE 6: The reduced scattering spectra of bone sample measured before (1) and after administration of glycerol (2) during an hour. Black circles correspond to data presented in [41], and open circles correspond to data presented in [42].

In the near infrared (NIR) spectral range, the absorption bands of water with maximums at $978,1192,1464$, and $1930 \mathrm{~nm}$ are observed [43, 44]. Absorption band with maximum at $1745 \mathrm{~nm}$ corresponds to absorption band of lipids [45]. Comparison of the data obtained in this study and presented by other authors $[41,42]$ shows accordance between them in the spectral range $800-1000 \mathrm{~nm}$. Insignificant differences between these data can be explained by differences in the used measuring techniques and the tissue samples preparation and storage methods [46].

It is well seen that administration of hyperosmotic solutions into cranial bone tissue allows for effective controlling its optical properties in NIR range. The transparence of the bone increases due to matching of the refractive indices of the hydroxyapatite matrix and the interstitial substance. Scatterers in bone tissues are large osteons with diameter $200-300 \mu \mathrm{m}$ and cavities between osteons with diameter 50 $90 \mu \mathrm{m}$ as well as nanostructures that cause complex character of light scattering.

Figure 6 shows that the reduced scattering coefficient decreases with wavelength increasing, which, in general, corresponds to spectral behaviour of the scattering characteristics of most of tissues [5, 37, 39]. A comparison of the data obtained by us in the spectral range 800 $950 \mathrm{~nm}$ with the data presented by Ugryumova et al. [41] and Firbank et al. [42] shows an accordance between them (see Figures 5 and 6). Discrepancy between these data does not prevail 20\% [46]. In the spectral range from 1000 to $2000 \mathrm{~nm}$, the reduced scattering coefficient decreases nonmonotonically with increasing of wavelength with peaks corresponding to the absorption bands in contrast to spectral behaviour of bone scattering in the spectral range from 800 to $1000 \mathrm{~nm}$, where the reduced scattering coefficient decreases smoothly with wavelength increasing. It can be explained by significant decrease of the anisotropy factor in the range of water absorption bands that produces the increase of the reduced scattering coefficient and appearance of bands in its spectrum $[47,48]$.

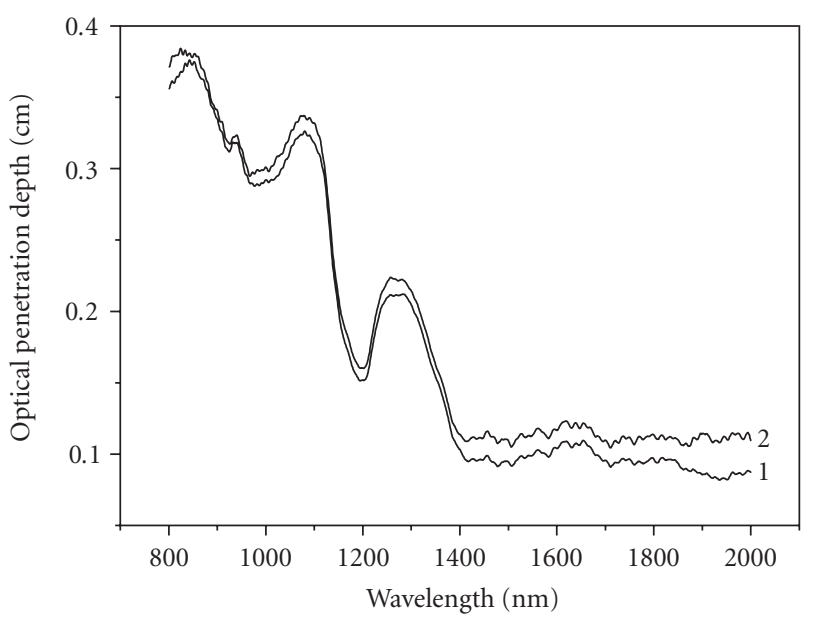

FIgURE 7: The optical penetration depth $\delta$ of light into human bone tissue over the wavelength range from 800 to $2000 \mathrm{~nm}$ before (1) and after administration of glycerol (2) during an hour.

The decrease of both absorption and scattering coefficients of bone tissue under action of immersion agent (see Figures 5,6 ) is not uniform in the studied range. It is well seen that in the wavelength range from 800 to $1400 \mathrm{~nm}$, absorption coefficient of the bone sample does not change. In the range from 1400 to 2000, the decrease of the absorption coefficient is observed in the following way: the average decreasing was about $8 \%$ in the range $1400-1800 \mathrm{~nm}$ and about $20 \%$ in the range $1800-2000 \mathrm{~nm}$. It can be explained by replacing of bone water by the surrounding glycerol solution. Since bone absorption properties in the spectral ranges are determined by water absorption, then replacing of bone water by dehydrogenated glycerol produced decrease of bone absorption coefficient. Another explanation of the decreasing of the bone absorption coefficient can be connected with the change of regime of photon scattering from the multiple to a low-scattering mode. In this case, the increase of photons free path length should be observed and, thus, more photons pass the tissue layer almost without absorption.

The decrease of tissue reduced scattering coefficient is observed in whole studied wavelength range. With increasing of wavelength, the effect also becomes more significant. Analysis of the experimental results has shown that the average decreasing of the coefficient was about $2 \%$ in the range $800-1100 \mathrm{~nm}$, about $8 \%$ in the range $1100-1400 \mathrm{~nm}$, and about $30 \%$ in the range $1400-2000 \mathrm{~nm}$.

Numerous publications discuss the mechanisms of clearing of soft tissues (i.e., skin, dura mater, sclera, and others) $[5,15-20,49,50]$. The main mechanisms of light scattering reduction induced by immersion agents are (1) dehydration of tissue constituents, (2) partial replacement of the interstitial fluid by the immersion substance, and (3) structural modification or dissociation of collagen $[5,15-20,49,50]$. We may hypothesise that dissociation of collagen of bone is not of great importance for the clearing as it may be in soft tissues because of a rigid structure of bone tissue. We believe that the main role in the clearing process has the replacement of water in the interstitial space by the immersion substance 
that leads to matching of the refractive indices between tissue scatterers and ground matter. Both glycerol and propylene glycol, as hypersosmotic agents, stimulate diffusion flow of bulk water from tissue to surrounding agent solution which also leads to additional refractive index matching between scatterers and interstitial space materials. On the other hand, they prevent total dehydration of tissue due to holding water inside, as water dilutes initial agent solution [49].

The depth penetration of light into a biological tissue is an important parameter for the correct determination of the irradiation dose in photothermal and photodynamic therapy of various diseases [5]. Estimation of the light penetration depth $\delta$ can be performed with the relation [51]

$$
\delta=\frac{1}{\sqrt{3 \mu_{a}\left(\mu_{a}+\mu_{s}^{\prime}\right)}} .
$$

Calculation of the optical penetration depth has been performed with the absorption and the reduced scattering coefficient values presented in Figures 5 and 6, respectively, and the result is presented in Figure 7. In Figure 7, it is seen that in dependence on the wavelength, the penetration depth varies considerably. The penetration depth is maximal in the spectral ranges $800-900 \mathrm{~nm}$ and $1000-1100 \mathrm{~nm}$, where the optical radiation penetrates up to depths of 0.32 $0.37 \mathrm{~cm}$ (light attenuation of 2.7-fold) in intact cranial bone. During an hour after administration of glycerol, the optical penetration depth increases by $5 \%$ in this spectral range. In the spectral range $1400-2000 \mathrm{~nm}$, the penetration depth increases more than $20 \%$.

\section{CONCLUSION}

The changes of optical properties of the human cranial bone in vitro under action of glycerol have been determined over the wavelength range $800-2000 \mathrm{~nm}$ using the integrating sphere technique and the inverse adding-doubling method. The reflectance change of the porcine cranial bone in vitro under action of propylene glycol has been determined over the wavelength range $450-1000 \mathrm{~nm}$ using the optical multichannel spectrometer. The decrease of both absorption and reduced scattering coefficient of the samples up to $20 \%$ and $30 \%$, respectively, under action of glycerol has been demonstrated. The decrease of bone reflectance under action of propylene glycol was up to $70 \%$.

The experiments have shown that administration of the immersion liquids allows for effective control of bone optical characteristics that makes bone more transparent, thereby increasing the ability of light penetration through the tissue. The presented results can be used in the developing of functional imaging techniques, including OCT and reflectance spectroscopy.

\section{ACKNOWLEDGMENTS}

The research described in this publication has been made possible, in part, by Grants of CRDF RNP.2.1.1.4473, Grant of RFBR no. 06-02-16740, and Russian Federation President's Grant no. 208-2008.2 “Supporting of Scientific
Schools." The authors would like to thank Professors V. I. Kochubey and Ms. N. A. Lakodina (Department of Optics and Biomedical Physics of Saratov State University) for the help in the experiments. They also would like to thank Dr. S. V. Eremina (Department of English and Intercultural Communication of Saratov State University) for the help in manuscript translation into English.

\section{REFERENCES}

[1] R. D. Frostig, Ed., In Vivo Optical Imaging of Brain Function, CRC Press, Boca Raton, Fla, USA, 2002.

[2] E. Gratton, V. Toronov, U. Wolf, M. Wolf, and A. Webb, "Measurement of brain activity by near-infrared light," Journal of Biomedical Optics, vol. 10, no. 1, Article ID 011008, 13 pages, 2005.

[3] S. Krishnamurthy, S. K. Powers, P. Witmer, and T. Brown, "Optimal light dose for interstitial photodynamic therapy in treatment for malignant brain tumors," Lasers in Surgery and Medicine, vol. 27, no. 3, pp. 224-234, 2000.

[4] V. X. D. Yang, P. J. Muller, P. Herman, and B. C. Wilson, "A multispectral fluorescence imaging system: design and initial clinical tests in intra-operative photofrin-photodynamic therapy of brain tumors," Lasers in Surgery and Medicine, vol. 32, no. 3, pp. 224-232, 2003.

[5] V. V. Tuchin, Tissue Optics: Light Scattering Methods and Instruments for Medical Diagnosis, SPIE Press Monograph Vol. PM166, SPIE Press, Bellingham, Wash, USA, 2nd edition, 2007.

[6] W. A. Kalender, "X-ray computed tomography," Physics in Medicine and Biology, vol. 51, no. 13, pp. R29-R43, 2006.

[7] Y. Chen, D. R. Tailor, X. Intes, and B. Chance, "Correlation between near-infrared spectroscopy and magnetic resonance imaging of rat brain oxygenation modulation," Physics in Medicine and Biology, vol. 48, no. 4, pp. 417-427, 2003.

[8] X. Wang, Y. Pang, G. Ku, X. Xie, G. Stoica, and L. V. Wang, "Noninvasive laser-induced photoacoustic tomography for structural and functional in vivo imaging of the brain," Nature Biotechnology, vol. 21, no. 7, pp. 803-806, 2003.

[9] D. A. Benaron, S. R. Hintz, A. Villringer, et al., "Noninvasive functional imaging of human brain using light," Journal of Cerebral Blood Flow and Metabolism, vol. 20, no. 3, pp. 469477, 2000.

[10] J. C. Hebden, A. Gibson, T. Austin, et al., "Imaging changes in blood volume and oxygenation in the newborn infant brain using three-dimensional optical tomography," Physics in Medicine and Biology, vol. 49, no. 7, pp. 1117-1130, 2004.

[11] F. Bevilacqua, D. Piguet, P. Marquet, J. D. Gross, B. J. Tromberg, and C. Depeursinge, "In vivo local determination of tissue optical properties: applications to human brain," Applied Optics, vol. 38, no. 22, pp. 4939-4950, 1999.

[12] W.-C. Lin, S. A. Toms, M. Johnson, E. D. Jansen, and A. Mahadevan-Jansen, "In vivo brain tumor demarcation using optical spectroscopy," Photochemistry and Photobiology, vol. 73, no. 4, pp. 396-402, 2001.

[13] D. A. Boas, "A fundamental limitation of linearized algorithms for diffuse optical tomography," Optics Express, vol. 1, no. 13, pp. 404-413, 1997.

[14] C. L. Smithpeter, A. K. Dunn, A. J. Welch, and R. RichardsKortum, "Penetration depth limits of in vivo confocal reflectance imaging," Applied Optics, vol. 37, no. 13, pp. 27492754, 1998. 
[15] V. V. Tuchin, "A clear vision for laser diagnostics (review)," IEEE Journal on Selected Topics in Quantum Electronics, vol. 13, no. 6, pp. 1621-1628, 2007.

[16] R. Cicchi, F. S. Pavone, D. Massi, and D. D. Sampson, "Contrast and depth enhancement in two-photon microscopy of human skin ex vivo by use of optical clearing agents," Optics Express, vol. 13, no. 7, pp. 2337-2344, 2005.

[17] I. V. Meglinski, A. N. Bashkatov, E. A. Genina, D. Y. Churmakov, and V. V. Tuchin, "The enhancement of confocal images of tissues at bulk optical immersion," Laser Physics, vol. 13, no. 1, pp. 65-69, 2003.

[18] E. D. Jansen, P. M. Pickett, M. A. Mackanos, and J. Virostko, "Effect of optical tissue clearing on spatial resolution and sensitivity of bioluminescence imaging," Journal of Biomedical Optics, vol. 11, no. 4, Article ID 041119, 7 pages, 2006.

[19] M. G. Ghosn, V. V. Tuchin, and K. V. Larin, "Depth-resolved monitoring of glucose diffusion in tissues by using optical coherence tomography," Optics Letters, vol. 31, no. 15, pp. 2314-2316, 2006.

[20] I. V. Larina, E. F. Carbajal, V. V. Tuchin, M. E. Dickinson, and K. V. Larin, "Enhanced OCT imaging of embryonic tissue with optical clearing," Laser Physics Letters, vol. 5, pp. 476-480, 2008.

[21] A. Boskey and R. Mendelsohn, "Infrared analysis of bone in health and disease," Journal of Biomedical Optics, vol. 10, no. 3, Article ID 031102, 9 pages, 2005.

[22] J. W. Ager III, R. K. Nalla, K. L. Breeden, and R. O. Ritchie, "Deep-ultraviolet Raman spectroscopy study of the effect of aging on human cortical bone," Journal of Biomedical Optics, vol. 10, no. 3, Article ID 034012, 8 pages, 2005.

[23] A. Pifferi, A. Torricelli, P. Taroni, et al., "Optical biopsy of bone tissue: a step toward the diagnosis of bone pathologies," Journal of Biomedical Optics, vol. 9, no. 3, pp. 474-480, 2004.

[24] J. Currey, “'Osteons' in biomechanical literature," Journal of Biomechanics, vol. 15, no. 9, p. 717, 1982.

[25] S. Weiner and H. D. Wagner, "The material bone: structuremechanical function relations," Annual Review of Materials Science, vol. 28, no. 1, pp. 271-298, 1998.

[26] A. S. Posner, "Bone mineral and the mineralisation process," in Bone and Mineral Research, W. A. Peck, Ed., Elsevier, Amsterdam, The Netherlands, 1987.

[27] J.-Y. Rho, L. Kuhn-Spearing, and P. Zioupos, "Mechanical properties and the hierarchical structure of bone," Medical Engineering \& Physics, vol. 20, no. 2, pp. 92-102, 1998.

[28] M. A. Fernández-Seara, S. L. Wehrli, and F. W. Wehrli, "Diffusion of exchangeable water in cortical bone studied by nuclear magnetic resonance," Biophysical Journal, vol. 82, no. 1, pp. 522-529, 2002.

[29] E. E. Wilson, A. Awonusi, M. D. Morris, D. H. Kohn, M. M. J. Tecklenburg, and L. W. Beck, "Three structural roles for water in bone observed by solid-state NMR," Biophysical Journal, vol. 90, no. 10, pp. 3722-3731, 2006.

[30] W. F. Neuman and M. W. Neuman, Skeletal Dynamics the Chemical Dynamics of Bone Mineral, University of Chicago Press, Chicago, Ill, USA, 1958.

[31] F. W. Wehrli and M. A. Fernández-Seara, "Nuclear magnetic resonance studies of bone water," Annals of Biomedical Engineering, vol. 33, no. 1, pp. 79-86, 2005.

[32] R. F. Robinson, "An electron-microscopy study of the crystalline inorganic component of bone and its relationship to the organic matrix," Journal of Bone and Joint Surgery, vol. 34A, no. 2, pp. 389-435, 1952.
[33] A. Ascenzi and C. Fabry, "Technique for dissection and measurement of refractive index of osteones," Journal of Biophysical and Biochemical Cytology, vol. 6, pp. 139-143, 1959.

[34] F. A. Duck, Physical Properties of Tissue: A Comprehensive Reference Book, Academic Press, London, UK, 1990.

[35] X.-J. Wang, T. E. Milner, M. C. Chang, and J. S. Nelson, "Group refractive index measurement of dry and hydrated type I collagen films using optical low-coherence reflectometry," Journal of Biomedical Optics, vol. 1, no. 2, pp. 212-216, 1996.

[36] V. V. Tuchin, Optical Clearing of Tissues and Blood, SPIE Press Monograph Vol. PM154, SPIE Press, Bellingham, Wash, USA, 2005.

[37] S. A. Prahl, M. J. C. van Gemert, and A. J. Welch, "Determining the optical properties of turbid media by using the addingdoubling method," Applied Optics, vol. 32, no. 4, pp. 559-568, 1993.

[38] A. N. Bashkatov, E. A. Genina, V. I. Kochubey, and V. V. Tuchin, "Optical properties of human skin, subcutaneous and mucous tissues in the wavelength range from 400 to $2000 \mathrm{~nm}$," Journal of Physics D, vol. 38, no. 15, pp. 2543-2555, 2005.

[39] D. K. Sardar, G.-Y. Swanland, R. M. Yow, R. J. Thomas, and A. T. C. Tsin, "Optical properties of ocular tissues in the near infrared region," Lasers in Medical Science, vol. 22, no. 1, pp. 46-52, 2007.

[40] S. A. Prahl, "Optical absorption of hemoglobin," 1999, http://omlc.ogi.edu/spectra/hemoglobin/.

[41] N. Ugryumova, S. J. Matcher, and D. P. Attenburrow, "Measurement of bone mineral density via light scattering," Physics in Medicine and Biology, vol. 49, pp. 469-483, 2004.

[42] M. Firbank, M. Hiraoka, M. Essenpreis, and D. T. Delpy, "Measurement of the optical properties of the skull in the wavelength range 650-950 nm," Physics in Medicine and Biology, vol. 38, no. 4, pp. 503-510, 1993.

[43] K. F. Palmer and D. Williams, "Optical properties of water in the near infrared," Journal of the Optical Society of America, vol. 64, no. 8, pp. 1107-1110, 1974.

[44] L. Kou, D. Labrie, and P. Chylek, "Refractive indices of water and ice in the $0.65-2.5 \mu \mathrm{m}$ spectral range," Applied Optics, vol. 32, no. 19, pp. 3531-3543, 1993.

[45] K. A. Martin, "Direct measurement of moisture in skin by NIR spectroscopy," Journal of the Society of Cosmetic Chemists, vol. 44, pp. 249-261, 1993.

[46] A. N. Bashkatov, E. A. Genina, V. I. Kochubey, and V. V. Tuchin, "Optical properties of human cranial bone in the spectral range from 800 to $2000 \mathrm{~nm}$," in Saratov Fall Meeting 2005: Optical Technologies in Biophysics and Medicine VII, vol. 6163 of Proceedings of SPIE, p. 11, Saratov, Russia, July 2006.

[47] Y. Du, X. H. Hu, M. Caiveau, X. Ma, G. W. Kalmus, and J. Q. Lu, "Optical properties of porcine skin dermis between $900 \mathrm{~nm}$ and $1500 \mathrm{~nm}$," Physics in Medicine and Biology, vol. 46, no. 1, pp. 167-181, 2001.

[48] J.-P. Ritz, A. Roggan, C. Isbert, G. Müller, H. J. Buhr, and C.-T. Germer, "Optical properties of native and coagulated porcine liver tissue between 400 and $2400 \mathrm{~nm}$," Lasers in Surgery and Medicine, vol. 29, no. 3, pp. 205-212, 2001.

[49] E. A. Genina, A. A. Korobko, A. N. Bashkatov, V. V. Tuchin, I. V. Yaroslavsky, and G. B. Altshuler, "Investigation of skin water loss and glycerol delivery through stratum corneum," in Saratov Fall Meeting 2006: Optical Technologies in Biophysics and Medicine VIII, vol. 6535 of Proceedings of SPIE, Saratov, Russia, September 2007. 
[50] J. Hirshburg, B. Choi, J. S. Nelson, and A. T. Yeh, "Collagen solubility correlates with skin optical clearing," Journal of Biomedical Optics, vol. 11, no. 4, Article ID 040501, 3 pages, 2006.

[51] J.-P. Ritz, A. Roggan, C. Isbert, G. Müller, H. J. Buhr, and C.-T. Germer, "Optical properties of native and coagulated porcine liver tissue between 400 and $2400 \mathrm{~nm}$," Lasers in Surgery and Medicine, vol. 29, no. 3, pp. 205-212, 2001. 

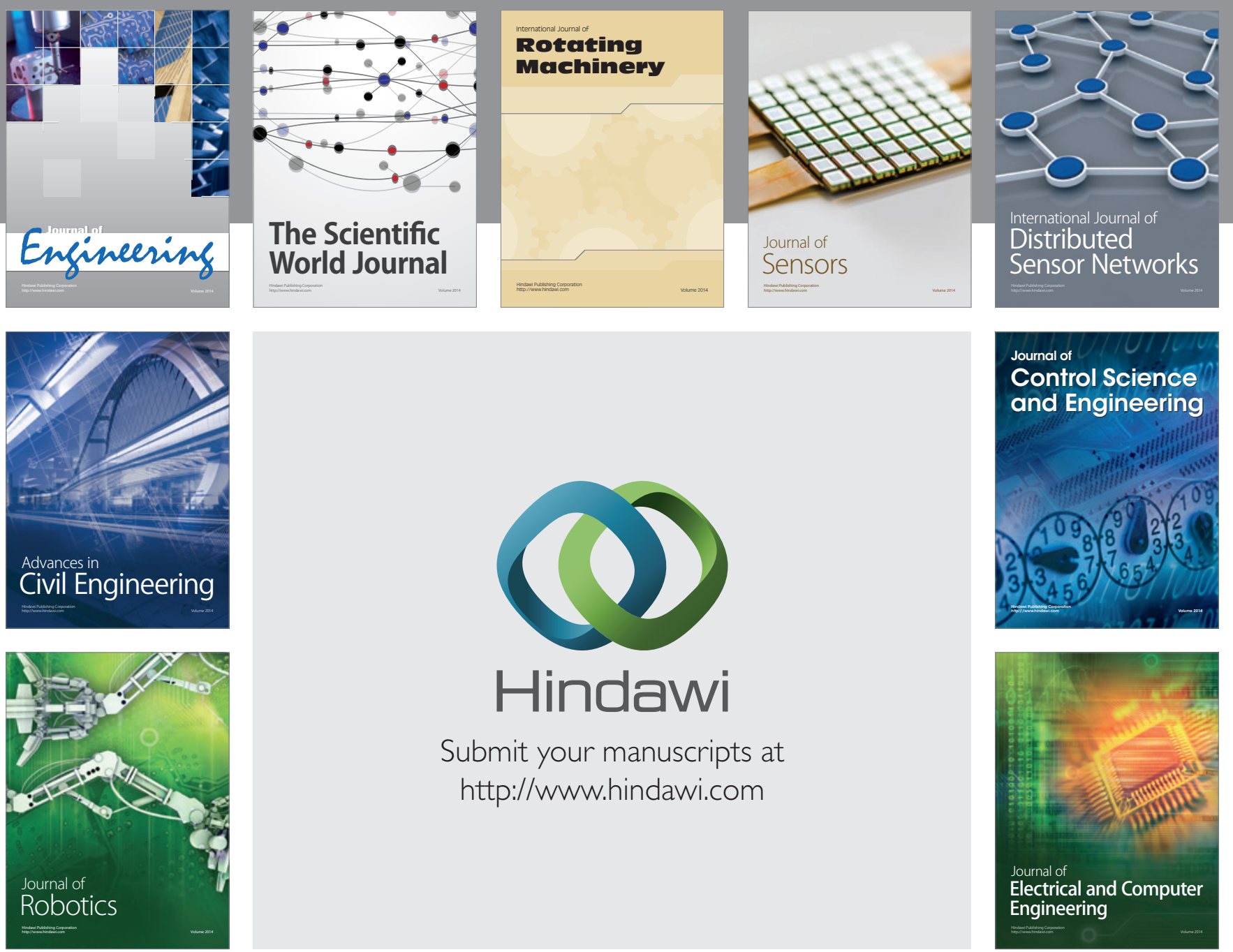

Submit your manuscripts at

http://www.hindawi.com
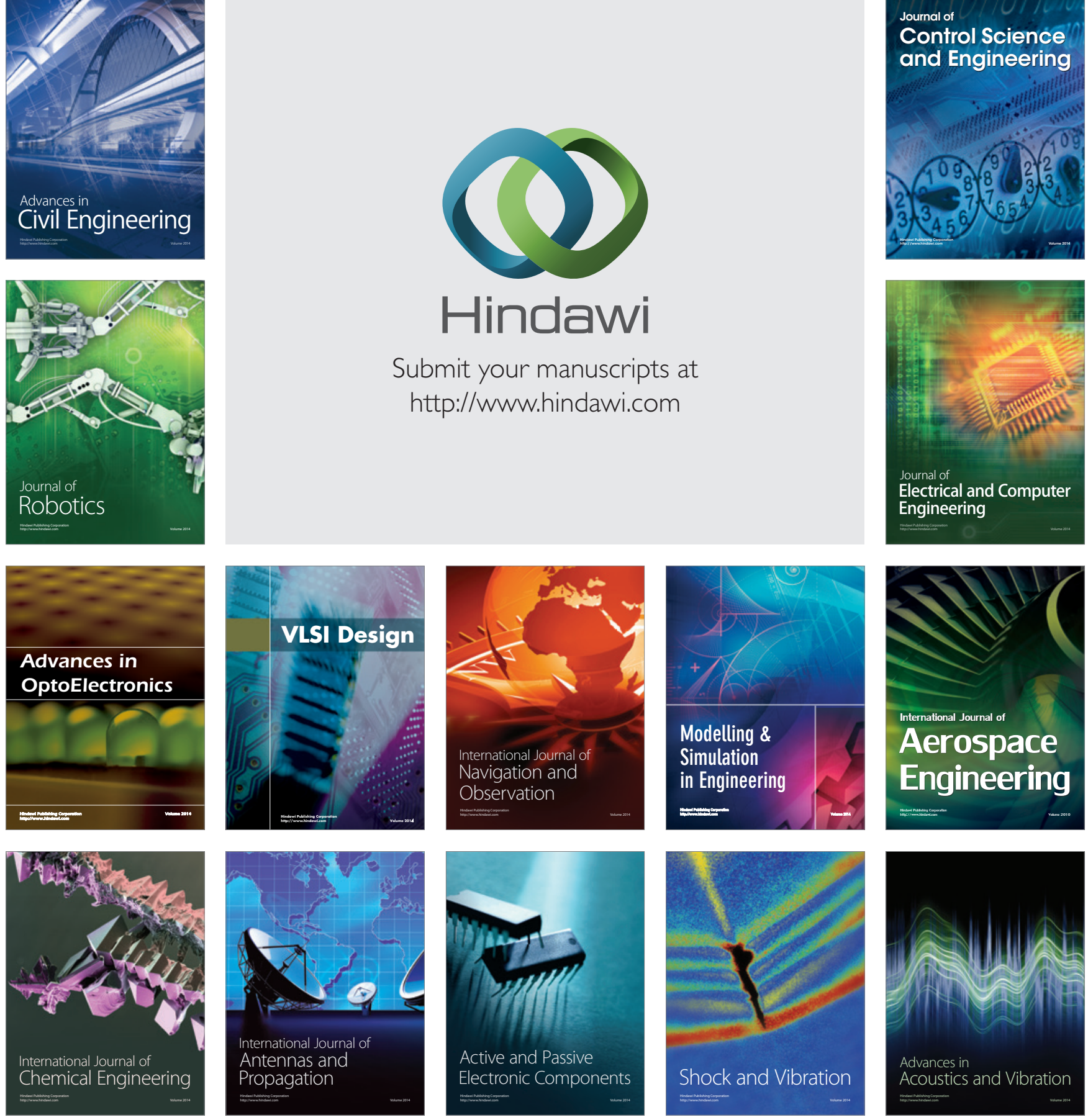